\title{
Multi-Objective Mathematical Model for the Optimal Time to Harvest Sugarcane
}

\author{
Surattana Sungnul1,2, Wisanlaya Pornprakun1,2, Santipong Prasattong1, Chanasak Baitiang1 \\ ${ }^{1}$ Department of Mathematics, King Mongkut's University of Technology North Bangkok, Bangkok, Thailand \\ ${ }^{2}$ Centre of Excellence in Mathematics, CHE, Bangkok, Thailand \\ Email: surattana.s@sci.kmutnb.ac.th,wisanlaya5140662031@hotmail.com,santipong.p@sci.kmutnb.ac.th,cbt@kmutnb.ac.th
}

How to cite this paper: Sungnul, S., Pornprakun, W., Prasattong, S. and Baitiang, C. (2017) Multi-Objective Mathematical Model for the Optimal Time to Harvest Sugarcane. Applied Mathematics, 8, 329-343. https://doi.org/10.4236/am.2017.83028

Received: February 7, 2017

Accepted: March 21, 2017

Published: March 24, 2017

Copyright ( 92017 by authors and Scientific Research Publishing Inc. This work is licensed under the Creative Commons Attribution International License (CC BY 4.0).

http://creativecommons.org/licenses/by/4.0/

(c) (i) Open Access

\begin{abstract}
In this paper, the sugarcane and sugar industry in Thailand is studied. The government determines the sugarcane prices which is based on the two main factors: 1) weight and 2) commercial cane sugar (standard value equal 10 C.C.S.). Usually, the C.C.S. will increase with time and the weight will decrease. The main purpose of this research is to find the optimal harvest time to maximize revenue and minimize gathering cost. The mathematical model is first formulated under the regulations of the Office of the Cane and Sugar Board (OCSB). The $\varepsilon$-constraints method is then applied to solve the multiobjective mathematical model. The optimal harvest times in the four regions of Thailand (Northern, Central, Eastern, North-Eastern) for crop years 2012/ $13,2013 / 14$ and 2014/15 are obtained for comparison.
\end{abstract}

\section{Keywords}

Multi-Objective Mathematical Model, Sugarcane, $\varepsilon$-Constraint Method

\section{Introduction}

Sugarcane is an important crop in Thailand because sugarcane is a raw material of the sugar industry, which is one of the top five agricultural products that makes revenue for the country each year. In the last ten years, the link between agriculture and industry and the structure of sugar markets have both changed. These changes have affected the amount and direction of the global sugar trade [1]. Thailand is an exporter with export volume ranked second in the world and and it also has a large role in the Asian market. Because Thailand has the advantage of location and an oversupply of sugar it can respond quickly to changes in demand in the Asian market. The forecast volume of exports in the next ten years is 11 million tons, which is an increase of 69 percent over the average 
volume of exports in the past ten years. Thus, sugarcane is an important economic crop in Thailand.

A survey by the Promotion Center of the Cane and Sugar Industry has reported that, in the crop year 2012/13 the average cost of production of sugarcane including the cost of transportation was 1196.31 baht per ton (transport cost was 143.61 baht per ton). This average cost of production was an increase of 246.31 baht per ton over the cost of 950 baht per ton in crop year 2011/12. This increase was because of increases in land rents and prices of labour, fertilizer and materials. In crop year 2012/13, sugarcane production for the whole country was at the level of 94.64 million tons from sugarcane plantations of 9.33 million rai for an average yield of 10.14 tons per rai. This production represented a decrease from crop year 2011/12 when the annual production was 97.98 million tons. The decrease occurred because of drought during the crop year 2012/13 when the rains came later than usual.

Many researchers have discussed the renewable energy which can be produced from the biomass of agricultural products. For example, the biomass can be used to produce ethanol which can then increase the profit and reduce the cost of the agricultural product. In 2008, Helenice de Oliveira Florentino [2] studied multi-objective optimization of the economics of sugarcane harvest biomass in Brazil. The aim of this work was to develop a model to optimize plant variety selection, to minimize cost of the residual biomass transfer process, to evaluate the economics of using this material, and to address sucrose production subject to planting area constraints, and considering distance from planting area to processing center. For this, 0 - 1 multiple objective linear programming techniques were used. The results showed the viability of the model when selecting varieties and the increased profit that could be obtained from residual biomass use. In 2010, Maximiliano Salles Scarpari and Edgar Gomes Ferreira de Beauclair [3] used linear programming to develop an optimized plan for sugarcane farming in Brazil. The program language used was General Algebraic Modelling System (GAMS) as this system was seen to be an excellent tool to allow profit maximization and harvesting time schedule optimization in the sugar mill studied. The results supported this optimized planning model as being a very useful tool for sugarcane management. In 2012, Francisco Regis Abreu Gomes [4] studied a bi-objective mathematical model for choosing sugarcane varieties with harvest residual biomass in energy co-generation. This study developed a biobjective mathematical model for choosing sugarcane varieties that result in maximum revenue from electricity sales and minimum gathering cost of sugarcane by harvesting residual biomass. The approach used to solve the proposed model was based on the $\varepsilon$-constraints method. Experiments were performed using real data from sugarcane varieties and costs and showed effectiveness of the model and method proposed. These experiments showed the possibility of increasing net revenue from electricity sale, i.e., discounting the cost increase with residual biomass gathering, by up to $98.44 \%$.

At present, the Thai government determines the price of sugarcane each year 
depending on its quality (sweetness) and weight. In general, the sweetness increases over time while the weight decreases. In this paper, a model is developed to find the optimal harvest time of sugarcane in order to maximize the agriculturists revenue and to minimize the cost. The mathematical model is formulated in a multi-objective optimization framework under the Office of Cane and Sugar Board (OCSB) conditions. The $\varepsilon$-constraints method is used to solve the multi-objective optimization problem. The results for production of fresh sugarcane (not burnt before cutting) and fired sugarcane (was burnt before cutting) in crop years 2012/13, 2013/14 and 2014/15 are compared and analyzed.

\section{Multi-Objective Optimization}

A multi-objective optimization problem has a number of objective functions which are to be minimized or maximized. As in a single-objective optimization problem, the problem usually has a number of constraints which any feasible solution (including the optimal solution) must satisfy. In its general form, the multi-objective optimization problem (MOOP) can be stated as follows (see, e.g., [5]):

$$
\begin{array}{ll}
\text { Minimize } & f_{m}(\boldsymbol{x}), m=1,2, \cdots, M \\
\text { subject to } & g_{j}(\boldsymbol{x}) \geq 0, j=1,2, \cdots, J \\
& h_{k}(\boldsymbol{x})=0, k=1,2, \cdots, K \\
& x_{i}^{(L)} \leq x_{i} \leq x_{i}^{(U)}, i=1,2, \cdots, n
\end{array}
$$

A solution $\boldsymbol{x}$ is a vector of $n$ decision variables : $\boldsymbol{x}=\left(x_{1}, x_{2}, \cdots, x_{n}\right)^{\mathrm{T}}$. The last set of constraints are called variable bounds as they restrict each decision variable $x_{i}$ to take a value within a lower bound $x_{i}^{(L)}$ and an upper bound $x_{i}^{(U)}$. The feasible region $D$ for the MOOP is the set of vectors $\boldsymbol{x}$ that satisfy all constraints. If each objective function $f_{m}(x)$ is denoted by $z_{m}$ and the vector of all objective functions is denoted by $\mathbf{z}$, then the objective function space can be defined as:

$$
Z=\left\{\mathbf{z}=\left(z_{1}, z_{2}, \cdots, z_{M}\right) \mid z_{m}=f_{m}(\boldsymbol{x}), \forall \boldsymbol{x} \in D, m=1,2, \cdots, M\right\}
$$

In this work, the $\varepsilon$-constraints method [5] was used to solve the MOOP. This method consists of reformulating a multi-objective problem by choosing the most important objective while maintaining other objectives constrained by upper bounds defined by a decision maker. For example, if $f_{\mu}(x)$ is selected as the most important objective, then the problem can be reformulated as follows:

$$
\begin{array}{ll}
\text { Minimize } & f_{\mu}(x) \\
\text { subject to } & f_{m}(x) \leq \varepsilon_{m}, m=1,2, \cdots, M ; m \neq \mu \\
& g_{j}(x) \geq 0, j=1,2, \cdots, J \\
& h_{k}(x)=0, k=1,2, \cdots, K \\
& x_{i}^{(L)} \leq x_{i} \leq x_{i}^{(U)}, i=1,2, \cdots, n
\end{array}
$$

where $\varepsilon_{m}$ is an upper bound of objective $m, m=1,2, \cdots, M ; m \neq \mu$ and $D$ is the set of feasible solutions to the $\varepsilon$-constrained problem. 


\section{Mathematical Model}

In this section, the mathematical model is formulated in a multi-objective optimization framework under the Office of the Cane and Sugar Board (OCSB) conditions. The main purpose is to find the optimal harvest time of sugarcane in order to maximize the agriculturists' revenue and minimize the cost. This problem is a bi-objective optimization problem to maximize revenue and minimize cost. For the $\varepsilon$-constraint formulation, the maximum of revenue from the sugarcane sale will be chosen as the objective function and the gathering cost of production of the sugarcane will be bounded above by an $\varepsilon$-constraint.

Revenue of selling: The government determines the sugarcane prices which are based on two main factors; 1) weight and 2) commercial cane sugar (C.C.S.).

1) Revenue from the weight of sugarcane: The OCSB classifies sugarcane going into factories into 2 types; a) fresh sugarcane and b) fired sugarcane. As determined by the government, agriculturists who sell fired sugarcane will have $20 \mathrm{baht} / \mathrm{ton}$ deducted from the price of sugarcane based on weight. The factory will share this amount of money between agriculturists who sell fresh sugarcane and increase their price based on weight by a maximum of $70 \mathrm{baht} / \mathrm{ton}$. The price of fired sugarcane based on weight $P_{w}(B)$ is therefore defined by

$$
P_{w}(B)=P_{w}-20 \text {, }
$$

where $P_{w}$ is the basic price of sugarcane based on weight set by the government (baht/ton). The price of fresh sugarcane based on weight $P_{w}(A)$ is defined by

$$
P_{w}(A)=P_{w}+\frac{20 a_{j, k}(B)}{a_{j, k}(A)},
$$

where $a_{j, k}(A)$ is the amount of fresh sugarcane (tons) from planted area $j$ in the harvest at time $k$ and $a_{j, k}(B)$ is the amount of fired sugarcane (tons) from planted area $j$ in the harvest at time $k$. Reasonable values for the total planted areas of sugarcane were estimated from OCSB data. The actual values for $a_{j, k}$ were computed by the optimization program.

Therefore the revenue from weight of sugarcane is defined by

$$
P_{1}(i)=P_{w}(i) a_{j, k}(i), \quad i=A, B
$$

2) Revenue from C.C.S. of sugarcane. The price per ton based on C.C.S is defined by

$$
P_{2}(i)=\left[P_{c}\left(1+0.06 y_{j, k}\right)\right] a_{j, k}(i), \quad i=A, B
$$

where $P_{c}$ is the price per ton determined by the government for sugarcane with 10 C.C.S.

$y_{j, k}=$ C.C.S. -10 , where C.C.S. is the average C.C.S. from sugarcane in planted area $j$ in the harvest at time $k$. The factor 0.06 is the rate of change of price per 1 C.C.S. change from the base level of 10.

Therefore, revenue $\left[R V_{j, k}(i)\right]$ from the sale of sugarcane from planted area 
$j$ in the harvest at time $k$ is determined by adding Equation (6) and Equation (7) as shown in Equation (8)

$$
R V_{j, k}(i)=P_{1}(i)+P_{2}(i)=\left\{P_{w}(i)+\left[P_{c}\left(1+0.06 y_{j, k}\right)\right]\right\} a_{j, k}(i), \quad i=A, B
$$

Gathering cost of production: The gathering cost of production can be separated into two parts: 1) average cost of production on the farm and 2) cost of transport. The total gathering cost $G C_{j, k}(i)$ baht/ton of sugarcane production from planted area $j$ in the harvest at time $k$ is given by

$$
G C_{j, k}(i)=\left(C_{j}+C_{T_{j}}\right) a_{j, k}(i), \quad i=A, B
$$

where $C_{j}$ is the average total cost of production of sugarcane on farms in area $j$ and $C_{T_{j}}$ is cost of transport to factories for sugarcane produced in area $j$. The average total cost of production $C_{j}$ consists of fixed costs such as farm rent and depreciation of equipment, and variable costs such as labor, materials and interest rates.

\subsection{The Mathematical Model of Fresh Sugarcane}

The multi-objective mathematical model of fresh sugarcane is described by Equations (10)-(13). The objective function Equation (10) maximizes revenue from the fresh sugarcane selling. The constraint Equation (11) represents the second objective of the problem which is to minimize gathering cost of production, with upper bound given by $\varepsilon_{e}$. The decision variables $X_{j, k}$ are defined by $X_{j, k}=1$ means that planted area $j$ is harvested at time $k$ and $X_{j, k}=0$ means that $j$ is not harvested at $k$. In the constraint set, Equation (12) and Equation (13) ensure that in each area the sugarcane is harvested only at one time $k$.

$$
\begin{gathered}
\text { Maximize } \sum_{j=1}^{m} \sum_{k=1}^{n} R V_{j, k}(A) \cdot X_{j, k} \\
\text { subject to } \sum_{j=1}^{m} \sum_{k=1}^{n} G C_{j, k}(A) \cdot X_{j, k} \leq \varepsilon_{e} \\
\sum_{k=1}^{n} X_{j, k}=1 ; \quad \forall j=1,2, \cdots, m \\
X_{j, k} \in\{0,1\} ; \quad \forall j=1,2, \cdots, m ; \quad \forall k=1,2, \cdots, n
\end{gathered}
$$

\subsection{The Mathematical Model of Fired Sugarcane}

The multi-objective mathematical model of fired sugarcane is described by Equations (14)-(17). The objective function Equation (14) maximizes revenue from the fired sugarcane selling. The constraint Equation (15) represents the second objective of the problem which is to minimize gathering cost of production, with upper bound given by $\varepsilon_{e}$. As for the fresh sugarcane model, the decision variables $X_{j, k}$ are defined by $X_{j, k}=1$ means that planted area $j$ is harvested at time $k$ and $X_{j, k}=0$ means that $j$ is not harvested at $k$. In the constraint set, Equation (16) and Equation (17) ensure that in each area the sugarcane is harvested only at one time $k$. 


$$
\begin{gathered}
\text { Maximize } \sum_{j=1}^{m} \sum_{k=1}^{n} R V_{j, k}(B) \cdot X_{j, k} \\
\text { subject to } \sum_{j=1}^{m} \sum_{k=1}^{n} G C_{j, k}(B) \cdot X_{j, k} \leq \varepsilon_{e} \\
\sum_{k=1}^{n} X_{j, k}=1 ; \quad \forall j=1,2, \cdots, m \\
X_{j, k} \in\{0,1\} ; \quad \forall j=1,2, \cdots, m ; \quad \forall k=1,2, \cdots, n
\end{gathered}
$$

Method of determining value of $\varepsilon_{e}$. The model will be solved for $p$ values of $\varepsilon_{e}$ defined as follows:

$$
\varepsilon_{e}=\varepsilon_{e-1}+\Delta \varepsilon ; \quad e=1,2, \cdots, p,
$$

where $\Delta \varepsilon=\frac{U B-L B}{p-1}$ and $L B$ and $U B$ are lower and upper bounds defined as follows.

$$
\begin{aligned}
L B= & \varepsilon_{1}(\text { summation of minimum of gathering cost in each area } j), \\
U B= & \varepsilon_{p}(\text { summation of maximum of gathering cost in each area } j) \text { and } \\
& p \text { is number of experiments. }
\end{aligned}
$$

\subsection{Technologies and Equipment Used}

The multi-objective mathematical models for fresh and fired sugarcane were solved using the linear programming and mixed-integer programming package GLPK (GNU Linear Programming Kit) version 4.52.

\subsection{Data Used in Experiments}

In this work, the optimal times to harvest sugarcane were determined for crop years 2012/13, 2013/14 and 2014/15. Examples of the real data used in the experiments for crop year 2012/13 are presented in Table 1 \& Table 2, respectively

Table 1 . The quantity of sugarcane $\left(\times 10^{5}\right.$ tons) delivered into factories in four regions of Thailand for crop year 2012/13.

\begin{tabular}{ccccccccc}
\hline Time & \multicolumn{2}{c}{ Northern } & \multicolumn{2}{c}{ Central } & \multicolumn{2}{c}{ Eastern } & \multicolumn{2}{c}{ North-Eastern } \\
\hline$(k)$ & Fresh & Fired & Fresh & Fired & Fresh & Fired & Fresh & Fired \\
\hline $15-30 / 11 / 12$ & 3.51 & 4.33 & 1.15 & 2.17 & 0.31 & 1.17 & 3.02 & 3.72 \\
$1-15 / 12 / 12$ & 6.80 & 13.74 & 3.77 & 8.79 & 0.53 & 2.99 & 17.98 & 18.03 \\
$16-31 / 12 / 12$ & 10.12 & 21.16 & 11.40 & 24.84 & 0.95 & 4.18 & 27.87 & 24.48 \\
$1-15 / 01 / 13$ & 10.45 & 21.42 & 14.48 & 29.75 & 1.29 & 4.31 & 22.60 & 24.29 \\
$16-31 / 01 / 13$ & 10.60 & 23.27 & 16.05 & 33.41 & 1.47 & 3.70 & 28.20 & 27.31 \\
$1-14 / 02 / 13$ & 8.80 & 20.68 & 11.64 & 25.15 & 1.41 & 3.55 & 22.35 & 28.09 \\
$15-28 / 02 / 13$ & 8.29 & 21.04 & 12.50 & 30.32 & 1.16 & 3.75 & 19.25 & 28.84 \\
$1-15 / 03 / 13$ & 6.78 & 23.25 & 11.77 & 30.43 & 1.05 & 3.62 & 15.95 & 32.13 \\
$16-31 / 03 / 13$ & 4.87 & 22.07 & 8.51 & 22.99 & 0.80 & 4.28 & 9.06 & 29.04 \\
$1-15 / 04 / 13$ & 0.55 & 4.50 & 1.83 & 4.04 & 0.35 & 2.98 & 1.99 & 11.95 \\
$16-30 / 04 / 13$ & 0.01 & 0.16 & 0.00 & 0.00 & 0.15 & 1.62 & 0.71 & 4.36 \\
$1-16 / 05 / 13$ & 0.00 & 0.00 & 0.00 & 0.00 & 0.07 & 1.16 & 0.10 & 0.88 \\
\hline
\end{tabular}


Table 2. The price of sugarcane and average total cost of production (baht/ton) in crop year 2012/13.

\begin{tabular}{ccccccc}
\hline $\begin{array}{c}P_{w}(A) \\
\text { (baht/ton) }\end{array}$ & $\begin{array}{c}P_{w}(B) \\
\text { (baht/ton) }\end{array}$ & $\begin{array}{c}P_{c} \\
\text { (baht/ton) }\end{array}$ & $\begin{array}{c}C_{\text {Norhern }} \\
\text { (baht/ton })\end{array}$ & $\begin{array}{c}C_{\text {Central }} \\
\text { (baht/ton) }\end{array}$ & $\begin{array}{c}C_{\text {Eastern }} \\
\text { (baht/ton) })\end{array}$ & $\begin{array}{c}C_{\text {North-Eastern }} \\
(\text { baht/ton })\end{array}$ \\
\hline 198.465 & 140 & 999.2 & 1113.49 & 1114.85 & 1077.65 & 963.45 \\
\hline
\end{tabular}

[6]. Table 1 shows quantity of fresh and fired sugarcane delivered to factories in the four regions of Thailand, Table 2 the price of the sugarcane and the average total cost of production, Table 3 shows the average C.C.S. of the sugarcane. The data in Table 3 were used to determine the values of the $y_{j, k}$ in the C.C.S. price $P_{2}(i)$ for the sugarcane in Equation (7).

A comparison of the quantities of fresh and fired sugarcane delivered to the sugar mills in the three crop years 2012/2013, 2013/2014 and 2014/2015 are shown in Figure 1. It can be seen that the percentages of fresh and fired sugarcane delivered are approximately $30 \%$ and $70 \%$, respectively.

\section{Results and Discussion}

The results of crop years 2012/13, 2013/14 and 2014/15 are presented in this section. The results are given for both fresh sugarcane and fired sugarcane for the four regions of Thailand.

\subsection{Results for Crop Year 2012/13}

The mathematical model for fresh sugarcane is described by objective function Equation (10) subject to constraints Equations (11)-(13) and the mathematical model for fired sugarcane is described by objective function Equation (14) subject to constraints Equations (15)-(17). The data from Tables 1-3 were used in the optimization. As stated earlier, the data in Table 3 were used to determine the values of the $y_{j, k}$ and the price $P_{2}(i)$ in Equation (7). The results are as follows.

1) Fresh Sugarcane :

The value of $\varepsilon_{e}$ was calculated from the formula in Equation (18). The values of the lower bound $L B=1.46 \times 10^{8}$ baht and upper bound $U B=5.84 \times 10^{9}$ baht were estimated for each region. In the computations, 100 values of $\varepsilon_{e}$ were used equally spaced between $L B$ and $U B$ in order to determine how the maximum revenue and the optimal cutting time changed as the upper bound on the gathering cost changed.

The results of revenue from the fresh sugarcane sales, gathering cost and the optimal harvest time for the four regions in Thailand; Northern, Central, Eastern and North-Eastern in each $\varepsilon_{e}$ are presented in Table 4. It was found that the revenue increased at a rate greater than the increase of cost as shown in Figure 2(a).

For example, for $\varepsilon_{2}$, the revenue would be $0.199 \times 10^{9}$ baht, the gathering cost would be $0.196 \times 10^{9}$ baht and the optimal harvest times in each area would be as follows: 1) Northern should be harvested in 16-30 April 2013, 2) 
Table 3. Average C.C.S. of sugarcane in crop year 2012/13.

\begin{tabular}{ccccc}
\hline Time $(k)$ & Northern & Central & Eastern & North-Eastern \\
\hline $15-30 / 11 / 12$ & 8.5 & 8.07 & 8.87 & 9.69 \\
$1-15 / 12 / 12$ & 8.79 & 8.59 & 9.24 & 10.77 \\
$16-31 / 12 / 12$ & 9.27 & 9.14 & 9.7 & 11.11 \\
$1-15 / 01 / 13$ & 9.7 & 9.54 & 10.01 & 11.4 \\
$16-31 / 01 / 13$ & 10.13 & 9.95 & 10.29 & 11.72 \\
$1-14 / 02 / 13$ & 10.44 & 10.2 & 10.45 & 11.96 \\
$15-28 / 02 / 13$ & 10.71 & 10.45 & 10.62 & 12.17 \\
$1-15 / 03 / 13$ & 10.92 & 10.66 & 10.76 & 12.34 \\
$16-31 / 03 / 13$ & 11.1 & 10.82 & 10.85 & 12.49 \\
$1-15 / 04 / 13$ & 11.19 & 10.89 & 10.93 & 12.56 \\
$16-30 / 04 / 13$ & 11.2 & 10.89 & 10.94 & 12.57 \\
$1-16 / 05 / 13$ & 11.2 & 10.89 & 10.93 & 12.56 \\
\hline
\end{tabular}

Table 4. The optimal harvest time for fresh sugarcane in $2012 / 13$ with $p=100$ experiments.

\begin{tabular}{ccccccc}
\hline$\varepsilon$ & Revenue & $\begin{array}{c}\text { Gathering } \\
\text { Cost }\end{array}$ & \multicolumn{3}{c}{ Optimal Time for Harvesting } \\
\hline & $\begin{array}{c}\left(\times 10^{9}\right. \\
\text { baht })\end{array}$ & $\begin{array}{c}\left(\times 10^{9}\right. \\
\text { baht })\end{array}$ & Northern & Central & Eastern & North-Eastern \\
\hline & 0.148 & 0.146 & $16-30 / 04 / 13$ & $15-30 / 11 / 12$ & $1-16 / 05 / 13$ & $1-16 / 05 / 13$ \\
\hline$\varepsilon_{1}$ & 0.199 & 0.196 & $16-30 / 04 / 13$ & $15-30 / 11 / 12$ & $1-15 / 12 / 12$ & $1-16 / 05 / 13$ \\
$\varepsilon_{2}$ & 0.288 & 0.253 & $16-30 / 04 / 13$ & $1-15 / 04 / 13$ & $1-15 / 04 / 13$ & $1-16 / 05 / 13$ \\
$\varepsilon_{3}$ & 0.371 & 0.312 & $16-30 / 04 / 13$ & $1-15 / 04 / 13$ & $1-15 / 04 / 13$ & $16-30 / 04 / 13$ \\
$\varepsilon_{4}$ & 0.439 & 0.359 & $16-30 / 04 / 13$ & $15-30 / 11 / 12$ & $1-15 / 04 / 13$ & $1-15 / 04 / 13$ \\
$\varepsilon_{5}$ & $\vdots$ & $\vdots$ & $\vdots$ & $\vdots$ & $\vdots$ & $\vdots$ \\
$\vdots$ & 6.907 & 5.724 & $16-31 / 01 / 13$ & $16-31 / 01 / 13$ & $1-15 / 04 / 13$ & $16-31 / 01 / 13$ \\
$\varepsilon_{98}$ & 6.963 & 5.772 & $16-31 / 01 / 13$ & $16-31 / 01 / 13$ & $16-31 / 03 / 13$ & $16-31 / 01 / 13$ \\
$\varepsilon_{99}$ & 7.041 & 5.844 & $16-31 / 01 / 13$ & $16-31 / 01 / 13$ & $16-31 / 01 / 13$ & $16-31 / 01 / 13$ \\
$\varepsilon_{100}$ & & & & & & \\
\hline
\end{tabular}

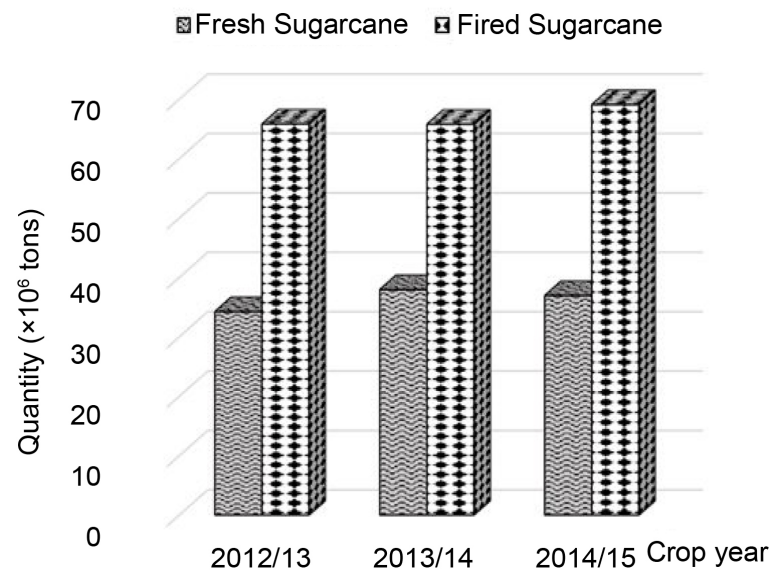

Figure 1. Comparison between quantities of fresh and fired sugarcane delivered to sugar mills. 


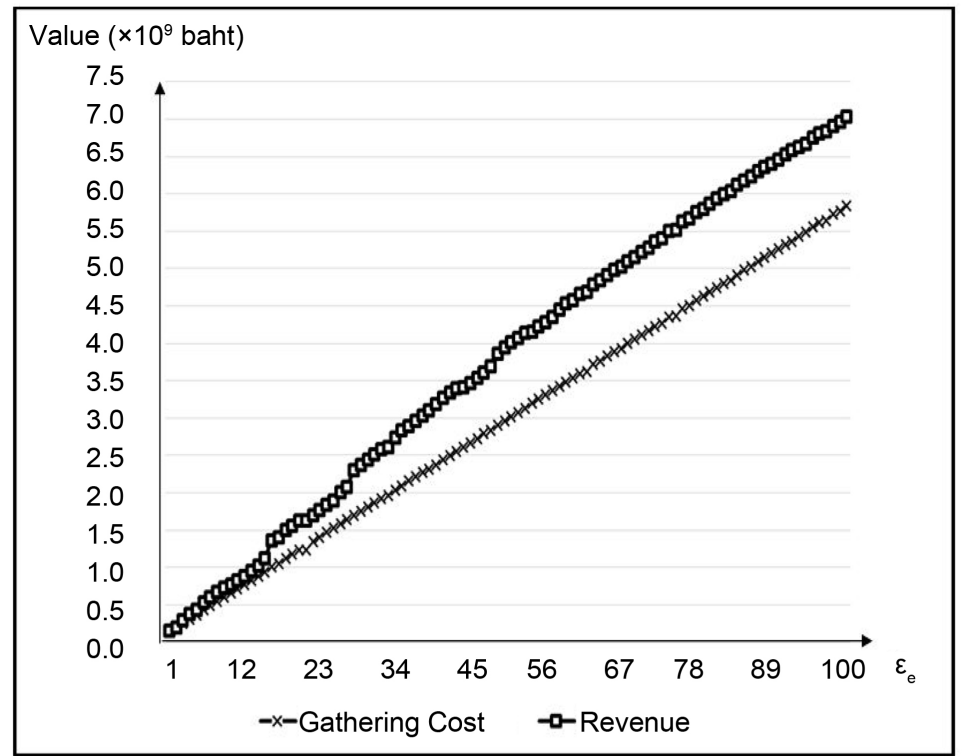

(a)

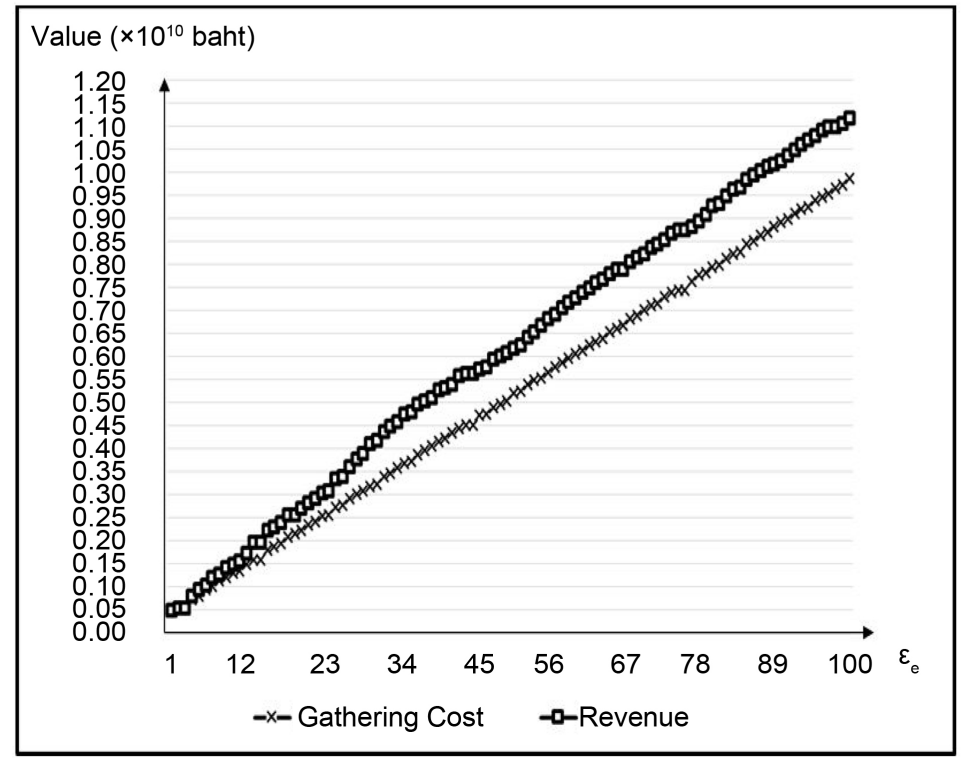

(b)

Figure 2. Comparison between revenue from sugarcane sales and gathering cost of production for 2012/2013. (a) Fresh Sugarcane. (b) Fired Sugarcane.

Central should be harvested in 15-30 November 2012, 3) Eastern should be harvested in 1-15 December 2012 and 4) North-Eastern should be harvested in 1-16 May 2013.

2) Fired Sugarcane :

The values of the $L B$ and $U B$ for gathering cost of the fired sugarcane were estimated as described for the fresh sugarcane. With these values, 100 values of $\varepsilon_{e}$ were used in the range $\varepsilon_{e} ; 4.69 \times 10^{8} \leq \varepsilon_{e} \leq 9.87 \times 10^{9}$. The calculated revenues from the fired sugarcane sales, gathering costs and the optimal 
harvest time for the four regions for each $\varepsilon_{e}$ are shown in Table 5. It was again found that the revenue increased at a rate greater than the increase of cost as shown in Figure 2(b).

For example, for $\varepsilon_{5}$, It was found that the optimal harvest times in each area were as follows: 1) Northern should be harvested in 16-30 April 2013, 2) Central should be harvested in 15-30 November 2012,3) Eastern should be harvested in 1-16 May 2013 and 4) North-Eastern should be harvested in 16-30 April 2013. The maximum values of revenue from the fired sugarcane selling would be $9.45 \times 10^{8}$ baht and the minimum values of gathering cost would be $8.05 \times 10^{8}$ baht.

\subsection{Results for Crop Year 2013/14}

The mathematical model for fresh sugarcane is described by objective function (10) subject to constraints (11)-(13) and the mathematical model of fired sugarcane is described by objective function (14) subject to constraints (15)-(17). Real data for crop year 2013/14 were used for the C.C.S. and the prices $P_{1}(i)$ for the weight, $P_{2}(i)$ for the C.C.S. and the gathering cost.

The results of revenues from the fresh and fired sugarcane sales, gathering costs and the optimal harvest time for the four regions in Thailand; Northern, Central, Eastern and North-Eastern for each $\varepsilon_{e}$ are presented in Table 6 and Table 7, respectively. It was found that in both cases the revenue increased at a rate greater than the increase of cost as shown in Figure 3(a) and Figure 3(b).

\subsection{Results for Crop Year 2014/15}

The mathematical model for fresh sugarcane is described by objective function (10) subject to constraints (11)-(13) and the mathematical model for fired sugarcane is described by objective function (14) subject to constraints (15)-(17). Real data for crop year 2014/15 were used for the C.C.S. and the prices $P_{1}(i)$ for the weight, $P_{2}(i)$ for the C.C.S. and the gathering cost.

Table 5. The optimal harvest time for fired sugarcane in 2012/13 with $p=100$ experiments.

\begin{tabular}{|c|c|c|c|c|c|c|}
\hline \multirow[t]{2}{*}{$\varepsilon$} & \multirow{2}{*}{$\begin{array}{c}\text { Revenue } \\
\begin{array}{c}\left(\times 10^{9}\right. \\
\text { baht })\end{array}\end{array}$} & \multirow{2}{*}{$\begin{array}{c}\text { Gathering } \\
\text { Cost }\end{array}$} & \multicolumn{4}{|c|}{ Optimal Time for Harvesting } \\
\hline & & & Northern & Central & Eastern & North-Eastern \\
\hline$\varepsilon_{1}$ & 0.493 & 0.469 & $16-30 / 04 / 13$ & $15-30 / 11 / 12$ & $1-16 / 05 / 13$ & $1-16 / 05 / 13$ \\
\hline$\varepsilon_{2}$ & 0.549 & 0.519 & $16-30 / 04 / 13$ & $15-30 / 11 / 12$ & $16-30 / 04 / 13$ & $1-16 / 05 / 13$ \\
\hline$\varepsilon_{3}$ & 0.549 & 0.519 & $16-30 / 04 / 13$ & $15-30 / 11 / 12$ & $16-30 / 04 / 13$ & $1-16 / 05 / 13$ \\
\hline$\varepsilon_{4}$ & 0.808 & 0.727 & $16-30 / 04 / 13$ & $1-15 / 04 / 13$ & $16-30 / 04 / 13$ & $1-16 / 05 / 13$ \\
\hline$\varepsilon_{5}$ & 0.945 & 0.805 & $16-30 / 04 / 13$ & $15-30 / 11 / 12$ & $1-16 / 05 / 13$ & $16-30 / 04 / 13$ \\
\hline$\vdots$ & $\vdots$ & $\vdots$ & $\vdots$ & $\vdots$ & $\vdots$ & $\vdots$ \\
\hline$\varepsilon_{98}$ & 10.995 & 9.667 & $16-31 / 03 / 13$ & $16-31 / 01 / 13$ & $1-15 / 03 / 13$ & $1-15 / 03 / 13$ \\
\hline$\varepsilon_{99}$ & 11.076 & 9.739 & $16-31 / 03 / 13$ & $16-31 / 01 / 13$ & $16-31 / 03 / 13$ & $1-15 / 03 / 13$ \\
\hline$\varepsilon_{100}$ & 11.192 & 9.869 & $1-15 / 03 / 13$ & $16-31 / 01 / 13$ & $16-31 / 03 / 13$ & $1-15 / 03 / 13$ \\
\hline
\end{tabular}


Table 6. The optimal harvest time for fresh sugarcane in 2013/14 with $p=100$ experiments.

\begin{tabular}{ccccccc}
\hline$\varepsilon$ & Revenue & $\begin{array}{c}\text { Gathering } \\
\text { Cost }\end{array}$ & & Optimal Time for Harvesting & \\
\hline & $\begin{array}{c}\left(\times 10^{9}\right. \\
\text { baht })\end{array}$ & $\begin{array}{c}\left(\times 10^{9}\right. \\
\text { baht })\end{array}$ & Northern & Central & Eastern & North-Eastern \\
\hline$\varepsilon_{1}$ & 0.096 & 0.083 & $25-30 / 11 / 13$ & $1-15 / 04 / 14$ & $16-30 / 04 / 14$ & $1-9 / 05 / 14$ \\
$\varepsilon_{2}$ & 0.149 & 0.136 & $25-30 / 11 / 13$ & $1-15 / 04 / 14$ & $1-15 / 12 / 13$ & $1-9 / 05 / 14$ \\
$\varepsilon_{3}$ & 0.249 & 0.210 & $1-15 / 04 / 14$ & $1-15 / 04 / 14$ & $16-30 / 04 / 14$ & $1-9 / 05 / 14$ \\
$\varepsilon_{4}$ & 0.315 & 0.272 & $25-30 / 11 / 13$ & $1-15 / 04 / 14$ & $16-31 / 03 / 14$ & $16-30 / 04 / 14$ \\
$\varepsilon_{5}$ & 0.409 & 0.342 & $1-15 / 04 / 14$ & $1-15 / 04 / 14$ & $1-15 / 12 / 13$ & $16-30 / 04 / 14$ \\
$\vdots$ & $\vdots$ & $\vdots$ & $\vdots$ & $\vdots$ & $\vdots$ & $\vdots$ \\
$\varepsilon_{98}$ & 7.937 & 6.684 & $16-31 / 01 / 14$ & $16-31 / 01 / 14$ & $16-31 / 03 / 14$ & $16-31 / 01 / 14$ \\
$\varepsilon_{99}$ & 7.937 & 6.684 & $16-31 / 01 / 14$ & $16-31 / 01 / 14$ & $16-31 / 03 / 14$ & $16-31 / 01 / 14$ \\
$\varepsilon_{100}$ & 8.083 & 6.828 & $16-31 / 01 / 14$ & $16-31 / 01 / 14$ & $16-31 / 01 / 14$ & $16-31 / 01 / 14$ \\
\hline & & & & & & \\
\hline
\end{tabular}

Table 7. The optimal harvest time for fired sugarcane in $2013 / 14$ with $p=100$ experiments.

\begin{tabular}{ccccccc}
\hline$\varepsilon$ & Revenue & $\begin{array}{c}\text { Gathering } \\
\text { Cost }\end{array}$ & \multicolumn{3}{c}{ Optimal Time for Harvesting } \\
\hline & $\begin{array}{c}\left(\times 10^{9}\right. \\
\text { baht })\end{array}$ & $\begin{array}{c}\left(\times 10^{9}\right. \\
\text { baht })\end{array}$ & Northern & Central & Eastern & North-Eastern \\
\hline$\varepsilon_{1}$ & 0.165 & 0.153 & $16-30 / 04 / 14$ & $1-15 / 04 / 14$ & $1-9 / 05 / 14$ & $25-30 / 11 / 13$ \\
$\varepsilon_{2}$ & 0.271 & 0.251 & $16-30 / 04 / 14$ & $1-15 / 04 / 14$ & $1-15 / 12 / 13$ & $1-9 / 05 / 14$ \\
$\varepsilon_{3}$ & 0.399 & 0.338 & $1-15 / 04 / 14$ & $1-15 / 04 / 14$ & $1-9 / 05 / 14$ & $1-9 / 05 / 14$ \\
$\varepsilon_{4}$ & 0.481 & 0.428 & $1-15 / 04 / 14$ & $1-15 / 04 / 14$ & $1-15 / 12 / 13$ & $1-9 / 05 / 14$ \\
$\varepsilon_{5}$ & 0.577 & 0.507 & $1-15 / 04 / 14$ & $1-15 / 04 / 14$ & $1-15 / 04 / 14$ & $1-9 / 05 / 14$ \\
$\vdots$ & $\vdots$ & $\vdots$ & $\vdots$ & $\vdots$ & $\vdots$ & $\vdots$ \\
$\varepsilon_{98}$ & 11.955 & 10.219 & $1-15 / 03 / 14$ & $15-28 / 02 / 14$ & $1-15 / 03 / 14$ & $16-31 / 03 / 14$ \\
$\varepsilon_{99}$ & 11.955 & 10.219 & $1-15 / 03 / 14$ & $15-28 / 02 / 14$ & $1-15 / 03 / 14$ & $16-31 / 03 / 14$ \\
$\varepsilon_{100}$ & 12.194 & 10.711 & $16-31 / 12 / 13$ & $16-31 / 01 / 14$ & $1-15 / 03 / 14$ & $16-31 / 03 / 14$ \\
\hline
\end{tabular}

1) Fresh Sugarcane.

The results of revenues from the fresh sugarcane sales, gathering costs, values of $\varepsilon_{e}$ and the optimal harvest time for the four regions in Thailand: Northern, Central, Eastern and North-Eastern for each $\varepsilon_{e}$ are presented in Table 8. As shown in Figure 4(a), it was found that for this crop year only $20 \%$ of the $\varepsilon_{e}$ values gave revenue greater than the gathering cost.

2) Fired Sugarcane.

For this crop year it was found, as shown in Figure 4(b), that the revenue was less than the gathering cost for all $\varepsilon_{e}$. Therefore there was no optimal harvest time in this case.

\subsection{Summary of Results}

A summary of the optimal harvest times for fresh and fired sugarcane for the crop years 2012/13, 2013/14 and 2014/15 are shown in Table 9 and Table 10. 


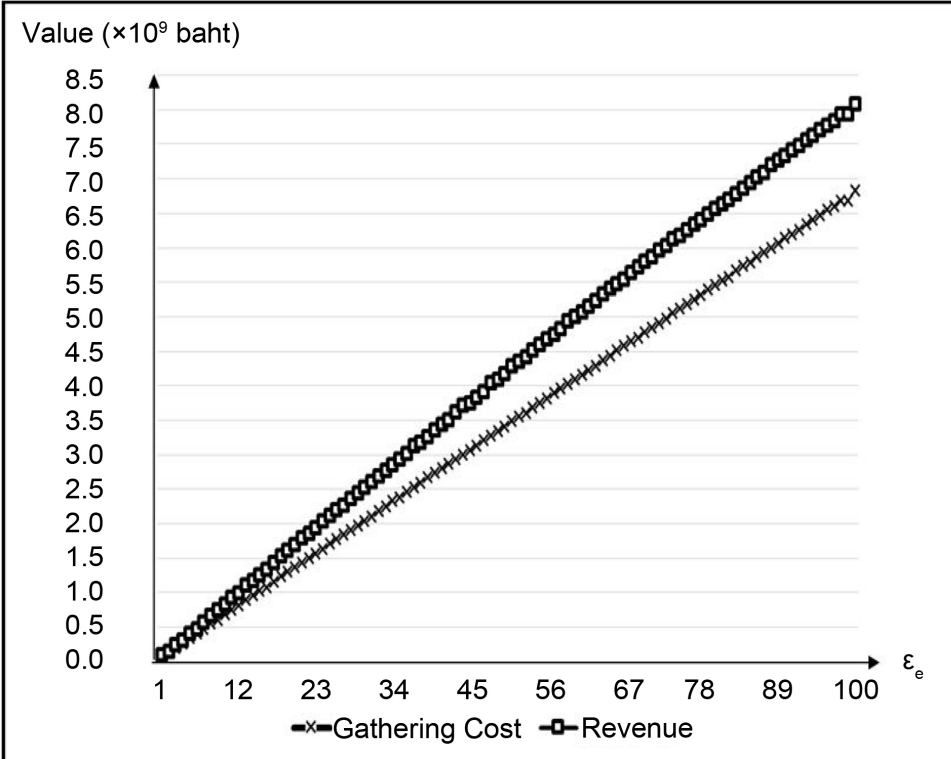

(a)

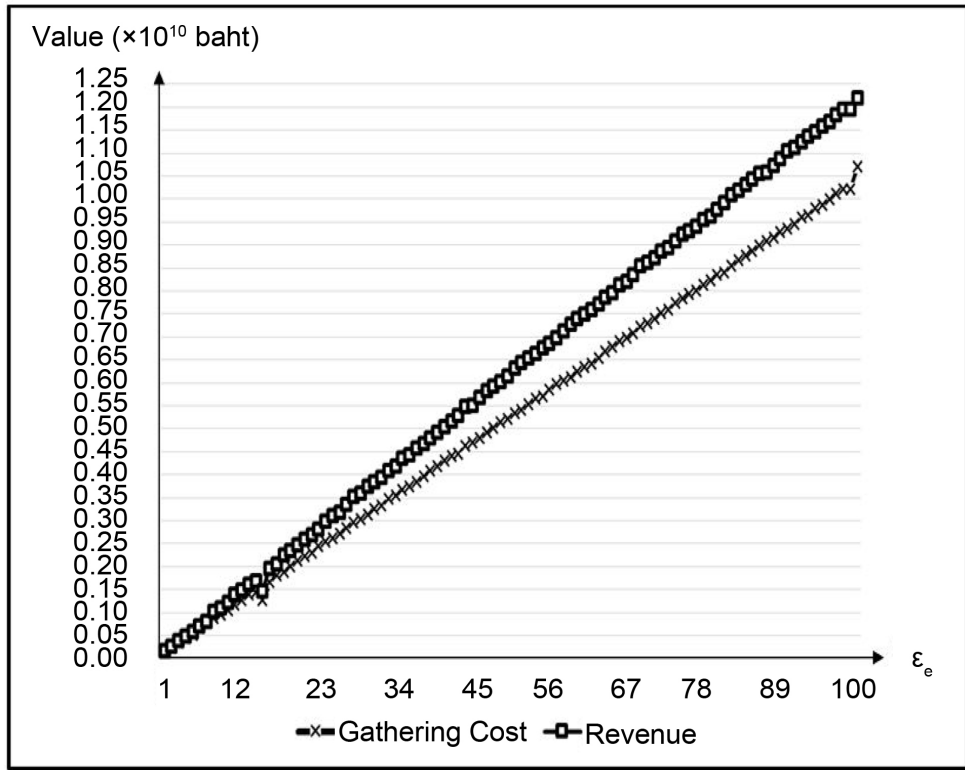

(b)

Figure 3. Comparison between revenue from sugarcane sales and gathering cost of production for 2013/2014. (a) Fresh Sugarcane; (b) Fired Sugarcane.

\section{Conclusions}

In this paper, a multi-objective mathematical model has been presented for the calculation of the optimal times to harvest fresh and fired sugarcane in Thailand for the crop years 2012/13, 2013/14 and 2014/15. The two objectives in the model were to maximize revenue and minimize cost. The $\varepsilon$-constraint method was used to change the multi-objective optimization model into a single-objective model to maximize revenue subject to an $\varepsilon$-constraint of an upper limit on the cost. The GNU Linear Programming Kit version 4.52 was used to compute 


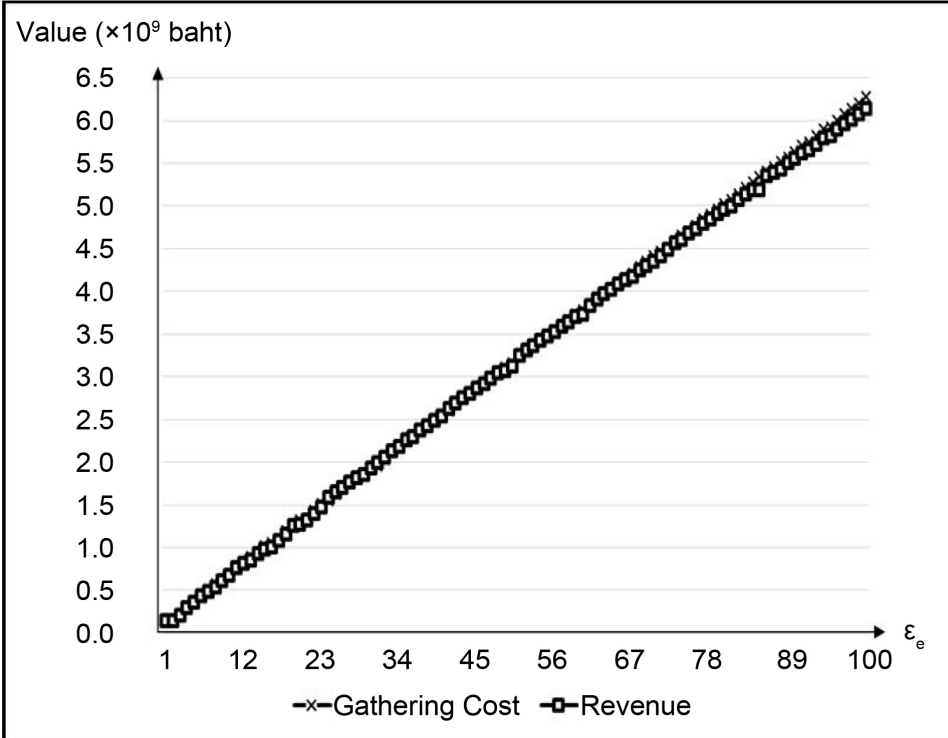

(a)

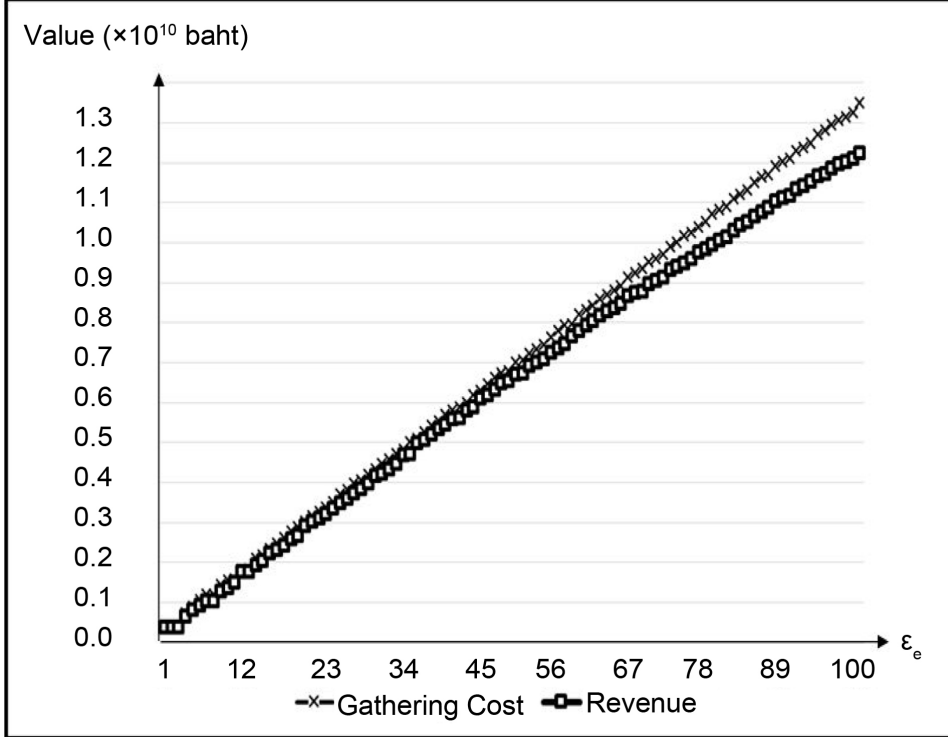

(b)

Figure 4. Comparison between revenue from sugarcane sales and gathering cost of production for 2014/2015. (a) Fresh Sugarcane; (b) Fired Sugarcane.

the optimal harvest time, maximum revenue and minimum gathering cost for a range of 100 values of $\varepsilon$-constraint. The results of the computations are summarized in Table 9 and Table 10.

The results show that the methods used in this paper can be used to predict optimal harvesting times. In this model, the main factor in determining the optimal harvest time is the change in C.C.S. with time as shown in Table 3. However, there are a number of other factors that are not included in the model that could change the optimal harvest times. These factors include: 1) changes in fixed and variable production costs during a year, 2) changes in delivery costs 
Table 8. The optimal harvest time for fresh sugarcane in $2014 / 15$ with $p=100$ experiments.

\begin{tabular}{ccccccc}
\hline$\varepsilon$ & Revenue & $\begin{array}{c}\text { Gathering } \\
\text { Cost }\end{array}$ & \multicolumn{5}{c}{ Optimal Time for Harvesting } \\
\hline & $\begin{array}{c}\left(\times 10^{9}\right. \\
\text { baht })\end{array}$ & $\begin{array}{c}\left(\times 10^{9}\right. \\
\text { baht })\end{array}$ & Northern & Central & Eastern & North-Eastern \\
\hline$\varepsilon_{1}$ & 0.145 & 0.151 & - & - & - & - \\
$\varepsilon_{2}$ & 0.145 & 0.151 & - & - & - & - \\
$\varepsilon_{3}$ & 0.212 & 0.224 & - & - & - & - \\
$\vdots$ & $\vdots$ & $\vdots$ & $\vdots$ & $\vdots$ & $\vdots$ & $\vdots$ \\
$\varepsilon_{24}$ & 1.588 & 1.556 & $16-30 / 04 / 15$ & $1-15 / 04 / 15$ & $1-15 / 04 / 15$ & $16-31 / 03 / 15$ \\
$\varepsilon_{25}$ & 1.655 & 1.630 & $16-30 / 04 / 15$ & $1-15 / 04 / 15$ & $16-31 / 03 / 15$ & $16-31 / 03 / 15$ \\
$\varepsilon_{26}$ & 1.698 & 1.689 & $16-30 / 04 / 15$ & $1-15 / 04 / 15$ & $1-15 / 12 / 14$ & $16-31 / 03 / 15$ \\
$\varepsilon_{27}$ & 1.765 & 1.754 & $16-30 / 04 / 15$ & $1-15 / 04 / 15$ & $15-28 / 02 / 15$ & $16-31 / 03 / 15$ \\
$\varepsilon_{28}$ & 1.815 & 1.812 & $16-30 / 04 / 15$ & $1-15 / 04 / 15$ & $1-14 / 02 / 15$ & $16-31 / 03 / 15$ \\
$\vdots$ & $\vdots$ & $\vdots$ & $\vdots$ & $\vdots$ & $\vdots$ & $\vdots$ \\
$\varepsilon_{99}$ & 6.075 & 6.201 & - & - & - & - \\
$\varepsilon_{100}$ & 6.143 & 6.273 & - & - & - & - \\
\hline & & & & & & $\vdots$
\end{tabular}

Table 9. Optimal harvesting times for fresh sugarcane.

\begin{tabular}{ccccc}
\hline Crop year & Northern & Central & Eastern & North-Eastern \\
\hline \multirow{2}{*}{$2012 / 2013$} & 16-30 April & 1-15 April 2013 & 1-15 April 2013 & 16-31 January \\
& 2013 & & & 2013 \\
$2013 / 2014$ & $1-15$ March & 15-28 February & $1-15$ April 2014 & 16-31 March \\
& 2014 & 2014 & & 2014 \\
$2014 / 2015$ & $16-30$ April & 1-15 April 2015 & $1-15$ April 2015 & 16-31 January \\
& 2015 & & & 2015 \\
\hline
\end{tabular}

Table 10. Optimal harvesting times for fired sugarcane.

\begin{tabular}{ccccc}
\hline Crop year & Northern & Central & Eastern & North-Eastern \\
\hline \multirow{2}{*}{ 2012/2013 } & 16-30 April & 1-15 April 2013 & 1-16 May 2013 & 1-15 March 2013 \\
& 2013 & & & \\
$2013 / 2014$ & 16-31 March & 1-15 March & 1-9 May 2014 & 16-30 April 2014 \\
& 2014 & 2014 & & \\
$2014 / 2015$ & $16-30$ April & 1-15 April 2015 & 1-15 April 2015 & 16-31 March 2015 \\
& 2015 & & & \\
\hline
\end{tabular}

during a year, 3) decisions by the sugar mills on their requirements for sugar cane.

\section{Acknowledgements}

This research was partially funded by King Mongkut's University of Technology North Bangkok (Contract No. KMUTNB-GOV-59-23) and Centre of Excellence in Mathematics, The Commission on Higher Education, Thailand. 


\section{References}

[1] Naranong, V., et al. (2013) A Study of Reform the Structure of Thailand's Sugar and Cane Industry. Thailand Development Research Institute.

[2] Florentino, H.O., Moreno, E.V. and Sartori, M.P. (2008) Multiobjective Optimization of Economic Balances of Sugarcane Harvest Biomass. Science Agricultural, 65, 561-564. https://doi.org/10.1590/s0103-90162008000500018

[3] Scarpari, M.S. and Ferreira, E.G. (2010) Optimized Agricultural Planning of Sugarcane Using Linear Programming. Revista Investigacion Operacional, 31, 126-132.

[4] Gomes, F.R.A. (2012) Bi-Objective Mathematical Model for Choosing Sugarcane Varieties with Harvest Residual Biomass in Energy Cogeneration. International Journal of Agricultural and Biological Engineering, 5, 50-58.

[5] Deb, K. (2001) Multi-Objective Optimization Using Evolutionary Algorithms. John Wiley and Sons, Chichester.

[6] Office of the Cane and Sugar Board. http://www.ocsb.go.th

Submit or recommend next manuscript to SCIRP and we will provide best service for you:

Accepting pre-submission inquiries through Email, Facebook, LinkedIn, Twitter, etc. A wide selection of journals (inclusive of 9 subjects, more than 200 journals)

Providing 24-hour high-quality service

User-friendly online submission system

Fair and swift peer-review system

Efficient typesetting and proofreading procedure

Display of the result of downloads and visits, as well as the number of cited articles

Maximum dissemination of your research work

Submit your manuscript at: http://papersubmission.scirp.org/

Or contact am@scirp.org 